\title{
Impacts of multiple stressors on freshwater biota across spatial scales and ecosystems
}

Sebastian Birk1,2,*, Daniel Chapman3,4, Laurence Carvalho3, Bryan M. Spears3, Hans Estrup Andersen5, Christine Argillier6, Stefan Auer7, Annette Baattrup-Pedersen5, Lindsay Banin3, Meryem Beklioğlus, Elisabeth Bondar-Kunze7, Angel Borja, Paulo Branco10, Tuba Bucak8,25, Anthonie D. Buijse 11, Ana Cristina Cardoso12, Raoul-Marie Couture 13,14, Fabien Cremona15, Dick de Zwart16, Christian K. Feld1,2, M. Teresa Ferreira10, Heidrun Feuchtmayr30, Mark O. Gessner17,38, Alexander Gieswein1, Lidija Globevnik18, Daniel Graeber5, 19, Wolfram Graf20, Cayetano Gutiérrez-Cánovas21,22, Jenica Hanganu23, Uğur Işkıns, Marko Järvinen24, Erik Jeppesens, Niina Kotamäki24, Marijn Kuijper 11, Jan U. Lemm1, Shenglan Lu37, Anne Lyche Solheim13, Ute Mischke26, S. Jannicke Moe 13, Peeter Nõges15, Tiina Nõges15, Steve J. Ormerod21, Yiannis Panagopoulos27,34, Geoff Phillips4, Leo Posthuma28,35, Sarai Pouso9, Christel Prudhomme3, Katri Rankinen36, Jes J. Rasmussen5, Jessica Richardson3, Alban Sagouis6,26,33, José Maria Santos10, Ralf B. Schäfer29, Rafaela Schinegger20, Stefan Schmutz20, Susanne C. Schneider 13, Lisa Schülting20, Pedro Segurado10, Kostas Stefanidis27,34, Bernd Sures 1,2 , Stephen J. Thackeray30, Jarno Turunen31, María C. Uyarra9, Markus Venohr26, Peter Carsten von der Ohe 32 , Nigel Willby4, Daniel Hering 1,2

${ }_{1}$ University of Duisburg-Essen, Faculty of Biology, Aquatic Ecology, Universitätsstraße 5, 45141 Essen, Germany

2 University of Duisburg-Essen, Centre for Water and Environmental Research, Universitätsstraße 5, 45141 Essen, Germany

${ }_{3}$ Centre for Ecology \& Hydrology, Freshwater Ecology Group, Bush Estate, Penicuik, Edinburgh EH26 0QB, United Kingdom

${ }_{4}$ University of Stirling, Biological and Environmental Sciences, Stirling FK9 4LA, United Kingdom

5 Aarhus University, Department of Bioscience, Vejlsøvej 25, 8600 Silkeborg, Denmark

6 Irstea, UR RECOVER, 3275 route de Cézanne, 13182 Aix-en-Provence, France

7 Wasser Cluster Lunz - Inter-university Center for Aquatic Ecosystem Research, Lunz am See, Dr. Carl Kupelwieser Promenade 5, 3293 Lunz/See, Austria

8 Middle East Technical University (METU), Limnology Laboratory, Biological Sciences Department, 06800 Ankara, Turkey

9 AZTI, Marine Research Division, Herrera Kaia, Portualdea s/n 20110 Pasaia, Spain

10 University of Lisbon, School of Agriculture, Forest Research Centre, Tapada da Ajuda, 1349-017 Lisbon, Portugal

11 Stichting Deltares, Daltonlaan 600, 3584 BK Utrecht, The Netherlands

12 European Commission, Directorate Joint Research Centre (JRC), Via E. Fermi 2749, 21027 Ispra VA, Italy 13 Norwegian Institute for Water Research (NIVA), Gaustadalléen 21, 0349 Oslo, Norway

14 Laval University, Department of Chemistry, 1045 av. de la Médecine, Québec (Québec), G1V 0A6, Canada 15 Estonian University of Life Sciences, Chair of Hydrobiology and Fishery, Institute of Agricultural and Environmental Sciences, 51006 Tartu, Estonia 16 MERMAYDE, Groet, The Netherlands

17 Leibniz-Institute of Freshwater Ecology and Inland Fisheries (IGB), Department of Experimental Limnology, Alte Fischerhütte 2, 16775 Stechlin, Germany

18 University of Ljubljana, Faculty of Civil and Geodetic Engineering, 1000 Ljubljana, Slovenia

19 Helmholtz-Centre for Environmental Research (UFZ), Department of Aquatic Ecosystem Analysis and

Management, Brückstr. 3a, 39114 Magdeburg

20 University of Natural Resources and Life Sciences, Institute of Hydrobiology and Aquatic Ecosystem

Management, Vienna, 1180 Vienna, Austria

${ }_{21}$ Cardiff University, School of Biosciences and Water Research Institute, Cardiff CF10 3AX, United Kingdom 
22 Freshwater Ecology, Hydrology and Management (FEHM) Research Group, Departament de Biologia Evolutiva, Ecologia i Ciències Ambientals, Universitat de Barcelona, Diagonal 643, 08028 Barcelona, Spain 23 Danube Delta National Institute for Research and Development, Babadag str. 165, 820112 Tulcea, Romania 24 Finnish Environment Institute (SYKE), Freshwater Centre, Survontie 9, 40500 Jyväskylä, Finland 25 Nature Conservation Centre, Aşağı Öveçler Mahallesi, 1293. Sokak. 06460 Çankaya, Ankara, Turkey 26 Leibniz-Institute of Freshwater Ecology and Inland Fisheries (IGB), Department of Ecohydrology, Müggelseedamm 310, 12587 Berlin, Germany 27 National Technical University of Athens, Center for Hydrology and Informatics, 15780 Athina, Greece 28 RIVM-Centre for Sustainability, Environment and Health (DMG), PO Box 1, 3720 BA Bilthoven, The Netherlands

29 University of Koblenz-Landau, Institute for Environmental Sciences, Quantitative Landscape Ecology, Fortstrasse 7, 76829 Landau, Germany 30 Centre for Ecology \& Hydrology, Lancaster Environment Centre, Library Avenue, Bailrigg, Lancaster, LA1 4AP, United Kingdom

31 Finnish Environment Institute (SYKE), Freshwater Centre, Linnanmaa K5, 90570 Oulu, Finland 32 Amalex Environmental Solutions, 04103 Leipzig, Germany

6533 Freie Universität Berlin, Department of Biology, Chemistry and Pharmacy, Königin-Luise-Straße 1-3, 14195 Berlin, Germany

6734 Hellenic Centre for Marine Research, Institute of Marine Biological Resources and Inland Waters, 19013 68 Anavissos Attikis, Greece

6935 Department of Environmental Science, Radboud University, Heyendaalseweg 135, Nijmegen, The $70 \quad$ Netherlands

7136 Finnish Environment Institute (SYKE), Freshwater Centre, Latokartanonkaari 11, 00790 Helsinki, Finland

72 37 DHI A/S - DHI Water Environment Health, Agern Allé 5, 2970 Hørsholm, Denmark

7338 Department of Ecology, Berlin Institute of Technology, Technical University of Berlin, Germany

74 * corresponding author: sebastian.birk@uni-due.de 
Abstract

Climate and land-use change drive a suite of stressors that shape ecosystems and interact

78 to yield complex ecological responses, i.e. additive, antagonistic and synergistic effects.

79 Currently we know little about the spatial scale relevant for the outcome of such interactions

80 and about effect sizes. This knowledge gap needs to be filled to underpin future land

81 management decisions or climate mitigation interventions, for protecting and restoring

82 freshwater ecosystems. The study combines data across scales from 33 mesocosm

83 experiments with those from 14 river basins and 22 cross-basin studies in Europe producing

84174 combinations of paired-stressor effects on a biological response variable. Generalised

85 linear models showed that only one of the two stressors had a significant effect in $39 \%$ of the analysed cases, $28 \%$ of the paired-stressor combinations resulted in additive and $33 \%$ in interactive (antagonistic, synergistic, opposing or reversal) effects. For lakes the frequency of additive and interactive effects was similar for all spatial scales addressed, while for rivers this frequency increased with scale. Nutrient enrichment was the overriding stressor for lakes, generally exceeding those of secondary stressors. For rivers, the effects of nutrient enrichment were dependent on the specific stressor combination and biological response variable. These results vindicate the traditional focus of lake restoration and management on nutrient stress, while highlighting that river management requires more bespoke management solutions. 


\section{Introduction}

Multiple stressors are increasingly recognized as a major concern for aquatic ecosystems and for those organisations in charge of their management1. Stressors commonly interact to affect freshwater species, communities and functions, but the questions remain to which degree this evidence from experiments can be transferred to field conditions and how relevant stressor interactions are for ecosystem management2. Critically, no study has been conducted to systematically confirm the frequency of occurrence of multiple stressor interactions across spatial scales (i.e. from waterbody to continental scales) and ecosystem types (i.e. for rivers and lakes). Using the most comprehensive large-scale assessment of multiple stressor interactions to date, we show that dominance of a single stressor, namely nutrient enrichment, is still common in lakes, while for rivers stressor interactions are much more relevant, demanding for more complex and informed management decisions.

Formerly, single, intense and well characterised stressors, such as organic and nutrient pollution from point sources, dominated freshwater ecosystem responses3. However, as these formerly dominant stressors are now controlled and others emerge, recent large-scale analyses have shown that freshwater ecosystems are exhibiting novel ecological responses to different stressors4,5,6.

For the simplest case of two stressors acting simultaneously, three main types of effects can be conceptually distinguished7: (i) Only one of the two stressors has notable ecological effects so that the effects of Stressor A outweigh those of Stressor B or vice versa (stressor dominance); (ii) the two stressors act independently such that their joint effect is the sum of the individual effects (additive effects); (iii) a stressor either strengthens or weakens the effects of the other (interaction). However, there is a striking lack of information on the frequency of occurrence of these effect types across spatial scales (i.e. from individual waterbodies to a whole continent) and ecosystem types (rivers $v s$. lakes)8.

Here we use a combined empirical-exploratory approach and a common quantitative framework to analyse a large set of original and compiled data on combinations of stressor pairs (explanatory variables), with each of them related to a biological response variable. We build on conceptual understanding of ecological responses to stressor interactions $9,10,11$ to structure an empirical modelling approach, using generalised linear modelling (GLM) and 174 stressor combinations with single biological responses from more than 18,000 observations (Figure 1). Outputs of the GLMs were interpreted to identify the frequency of cases with stressor dominance, additive stressor relationships and stressor interactions 
127 (synergistic or antagonistic), stratified by ecosystem type (lake or river) and spatial scale 128 (experiments, basin studies, cross-basin studies).

129 With this approach we addressed four questions: (1) How frequent are the three different

130 types of stressor effects in lakes and rivers? We expected a high share of additive and

131 interactive relationships in both lakes and rivers, as intense stressors obscuring the effects of

132 secondary stressors rarely occur nowadays12,13. (2) To what extent do ecosystem type (lake vs.

133 river) and spatial scale influence the combined effects of two stressors? We expected more

134 frequent stressor interactions in rivers, as their greater heterogeneity increases the likelihood

135 for two stressors to have an impact14. We further expected more frequent stressor interactions

136 in small-scale studies (i.e. in mesocosms), as these are less influenced by confounding

137 factors15,16. (3) What is the influence of ecosystem type (lake vs. river) and spatial scale on the

138 explanatory power of two stressors and their interaction? We expected the explanatory power

139 to be lower for rivers because of greater heterogeneity and thus potentially confounding

140 factors in comparison to lakes17. We also expected a decreasing explanatory power of

141 individual stressors and their interactions with spatial scale, reflecting the increasing

142 importance of confounding factors at large scales18,19. (4) Is nutrient enrichment still the most

143 prominent stressor affecting European aquatic ecosystems as suggested by 20, despite the

144 progress in wastewater cleaning, and does the importance of co-stressors differ between lakes

145 and rivers? We expected a dominating effect of nutrient stress in lakes due to the dominance

146 of primary producers and a greater relevance of hydrological and morphological changes in

147 rivers 21,22 .

148 Our study pursues a phenomenological approach (sensu 23) and seeks to disclose stressor

149 interrelations under "real-world" conditions, contributing to solve some of the pertinent issues

150 in ecosystem management2.

\section{Results and discussion}

\section{Impact of ecosystem type on stressor effect types}

154 Stressor interactions are regularly reported from the available synthesis papers on multiple 155 stressors in freshwater ecosystems 8,10. Therefore, we hypothesised that high proportions of 156 both lake and river case studies would indicate additive or interactive paired-stressor

157 relationships - this was not supported. Among the 174 cases, $39 \%$ of models indicated single 158 stressor dominance, $28 \%$ indicated additive paired-stressor effects, and $33 \%$ indicated paired 159 stressors interacting significantly (Figure 2; see also “Data and code availability”). 
We expected a higher proportion of river cases to exhibit stressor interactions, compared to lakes, as a result of greater habitat heterogeneity in rivers 14 - this was supported. The proportions of effect types differed between lakes (62\% dominance, $16 \%$ additive, $22 \%$ interactive) and rivers (28\% dominance, $33 \%$ additive, $39 \%$ interactive; see Figure 2) (Chisquared test, $p<0.001)$.

165 We assumed the different frequency of effect types between lakes and rivers might have been rooted in different frequencies of the stressor types investigated8: nutrient enrichment was one of the two stressors in $95 \%$ of the lake cases, but only in $76 \%$ of the river cases. However, these differences between lakes and rivers in the share of stressor dominance remain if only cases with nutrient enrichment are considered: 60\% (lakes) vs. 27\% (rivers), compared to $62 \%$ (lakes) vs. $29 \%$ (rivers) considering all cases.

171 There were also differences between lake and river cases in the frequency of organism 172 groups considered as response variables: for lakes, phytoplankton was the most frequently used organism group ( $76 \%$ of the cases) followed by fish (22\%), while in rivers benthic invertebrates (52\% of the cases) were dominating and fish were used in $21 \%$ of the cases.

175 However, when only regarding cases with fish as response variable, the differences in the share of dominant effect types is still high with $75 \%$ (lakes) $v s .32 \%$ (rivers). We therefore conclude that the observed differences in effect types between lakes and rivers are neither rooted in differences between the stressors nor in the organism groups investigated.

An alternative explanation is the different exposure of organisms inhabiting rivers and lakes to stressor effects. While freshwater ecosystems in general are sinks "collecting"

181 anthropogenic stressors, the much higher shoreline length of rivers multiplies the effects of human activities in the catchment, such as land and water uses24,25. This results in an increased exposure to hydrological and morphological stressors, the latter also being more relevant in rivers due to their primarily benthic habitats and assemblages26. This is also expected for toxic substances that can act more directly in (small) rivers, as much lower compound quantities are needed to reach toxic concentrations27. Within the 58 cases where models included a significant interaction term, the combinations of nutrients with toxic or morphological stress represented the greatest proportion of confirmed interaction effects (ratio of 0.45 or 0.43 , respectively; only combinations with total number of cases $>5$; no significant correlation between total number of cases and share of interactive cases). All but one of the cases with toxic substances as a stressor were rivers. 
We expected that the frequency of interactions would decrease with spatial scale - this was not supported. While for lakes additive and interactive effects did not differ significantly between scales, for rivers the share of additive and interactive cases increased with scale (Chisquared test, $\mathrm{p}<0.01$ ). Two contrasting mechanisms may explain this pattern: On the one hand, increasing spatial scale implies an increase in confounding factors (including stressors not addressed in this analysis and thus not tested), limiting the likelihood of detecting additive or interactive effects between the targeted stressors, as they may be masked by other factors not under investigation. On the other hand, increasing spatial scale implies longer stressor gradients. In fact, nutrient and hydrological stressor ranges significantly increase with scale (Kruskal-Wallis H-test, $p<0.001$ ), enhancing the likelihood of additive or interactive stressor effects, which may only occur at certain stressor intensities. The latter holds true only if stressors are effective over the whole gradient length, e.g. the biological response does not level off at low or intermediate stressor levels (as in case of nutrient saturation29,30).

As discussed above, the pattern of stressor dominance largely prevailed for lakes, irrespective of the spatial scale. Across the 34 cases of paired nutrient-thermal stress, however, the nutrient effects became more pronounced than the temperature effects with increasing spatial scale.

Though we are not aware of other studies comparing the effects of spatial scale on the explanatory power of stressor interactions models, the observed differences in the frequency of stressor interactions between experiments and field studies are in line with the synthesis studies of 8 and 10. While the study of Jackson et al.10 included only experiments and observed interactive or additive effect types in all cases considered, the study by Nõges et al.8 focussed on field studies and interactive or additive effect types were only given for $50 \%$ of the river and $15 \%$ of the lake cases.

\section{Impact of ecosystem type and spatial scale on the models' explanatory power}

European lakes are generally in a better condition than European rivers 20 and are affected by a lower number of stressors 31 . Therefore, we expected the explanatory power of our models to be lower for rivers because of greater impact of stressors that have not been regarded (i.e. confounding factors)8,32. Contrasting to our expectations, however, river models performed significantly better than lake models. This better performance can be explained by the specific nature of riverine ecosystems: rivers feature various niche and habitat factors that can be altered by multiple stressors (e.g. water quality, hydrology, benthic habitats), and the riverine fauna is sensitive to the impacted oxygen conditions, which may "collect" the effects 
of a variety of stressors into a single gradient. Oxygen, however, is rarely measured in a meaningful way in monitoring programs (including the daily maxima and minima) and was thus not considered as a stressor in our analysis. In contrast, lake phytoplankton seems less susceptible to the effects of multiple stressors, as long as nutrients are in the growth-limiting concentration range.

We expected a decreasing explanatory power with spatial scale, reflecting the increasing importance of confounding factors at large scales 18,19 - this was partly supported. The variance in biological response explained by the paired-stressor models (expressed as marginal $R_{2}$ ) ranged between 0.05 and 0.88 , with a median value of 0.19 . These ranges differed significantly between experiments (median marginal $R_{2}=0.38$ ), basin (median marginal $R_{2}=0.22$ ) and cross-basin studies (median marginal $R_{2}=0.16$ ) (Bonferronicorrected Mann-Whitney U-test, $p<0.05$; Figure 3A). The marginal $R 2$ differed significantly between lakes and rivers, with river cases showing on average slightly higher explanatory power (lakes: $R_{2}=0.15$, rivers: $R_{2}=0.22$; not shown). The importance of the interaction term (expressed as $\% R_{2}$ change) was significantly higher for lakes than for rivers. For rivers, this importance tended to decrease with increasing spatial scale of investigation, but differences between investigation scales were generally not significant (Figure 3B). We are not aware of a single other study targeting the role of spatial scale for the explanatory power of stressor interaction models.

For the experiments addressed in our study, the high level of control on potentially confounding factors can account for the on average greater explanatory power, when compared to field studies. Furthermore, the experimental studies had lower numbers of observations and less complex biological communities. Compared with this, factors such as temperature variation are already temporally pronounced at basin-scale and the spatial variation across basins is considerable.

\section{Role of nutrient stress for lakes vs. rivers}

The recent surveys by 8,20 suggest that eutrophication is still the most prominent stressor affecting the biota of Europe's water, in particular lakes, while rivers are also strongly affected by hydrological and morphological stressors. We therefore expected that responses to nutrient stress is retarded by the presence of secondary stressors in rivers more so than lakes where responses to nutrient enrichment are strongest 21,22 - this was supported.

We identified eleven combinations of nutrient stress paired with another stressor, covering morphological, hydrological (including hydropeaking), thermal, toxic and chemical stress (brownification) (Table 1). The number of analytical cases in each stressor combination 
ranged from four to 33, with the combinations including hydropeaking and brownification stress exclusively comprising data collected at the experimental scale. All other combinations comprised data from up to ten different studies, most of which originated from two or more spatial scales. Best represented were the combinations of nutrient stress paired with thermal stress affecting autotrophs in lakes, and nutrient stress paired with morphological stress affecting heterotrophs in rivers (Figure 4).

Table 1: Number of paired-stressor cases analysed across lakes and rivers

\begin{tabular}{|l|r|r|}
\hline Paired stressors & Lakes & Rivers \\
\hline Nutrient | Hydrological & 11 & 24 \\
\hline Nutrient | Morphological & 0 & 46 \\
\hline Nutrient | Thermal & 34 & 9 \\
\hline Nutrient | Toxic & 1 & 10 \\
\hline Nutrient | Chemical & 6 & 1 \\
\hline Hydrological | Morphological & 0 & 6 \\
\hline Hydrological | Thermal & 3 & 0 \\
\hline Hydrological | Chemical & & 0 \\
\hline Morphological | Morphological A & & 5 \\
\hline Morphological | Toxic & & 0 \\
\hline Morphological | Chemical & & 1 \\
\hline Toxic | Chemical & & 5 \\
\hline
\end{tabular}

A Connectivity disruption and morphological river alteration

Nutrient stress often had the stronger effect in the paired-stressor models. Hence, nine of

273 the eleven combinations in lakes and rivers showed a positive \%AES median, implying on 274 average stronger effects of nutrients compared to the other stressor. Five combinations even 275 showed a positive 25 th percentile $\%$ AES, indicating that in three quarters of the cases in these combinations nutrient effects outweighed the other stressors. This was evident for all lake stressor combinations except nutrients and brownification represented by a single case study.

278 The few additional lake cases, for which the non-nutrient stressor was stronger, included

279 warming affecting cyanobacterial biomass in European lakes, and lithophilous or piscivorous 280 fish abundance in French lakes.

281 The dominance of nutrients over secondary stressors in lakes applies, surprisingly, also to 282 temperature stress, which is often considered to interact in a synergistic way with 283 eutrophication in rivers and lakes33. One mesocosm experiment even demonstrated an 284 antagonistic relationship at high nutrient stress34. Water temperature may affect lake communities by modifying the food-web structure, e.g. by supporting planktivorous fish 35 ; the 
two temperature-driven functional fish-trait responses mentioned above perhaps indicate the emergence of such modification.

Brownification is a remarkable exception from this general pattern but observed here only in a single case study. It strongly superimposes the effects of nutrient stress, in particular by decreasing light transmission in the pelagic zone, which inhibits productivity despite excess nutrient concentrations (opposing interaction) and favours mixotrophic phytoplankton species. Brownification is triggered by global warming and wetter climate, and becomes increasingly relevant in boreal regions, as it originates from dissolved organic carbon in leachates of bogs and permafrost soils mineralising due to increasing temperatures and flushing, and the recovery from acidification36,37.

Rivers generally showed a more heterogeneous pattern: nutrients clearly affected autotrophs more strongly when paired with hydrological or morphological stress, and heterotrophs when paired with thermal stress. The few river cases in these combinations, for which the non-nutrient stressor was stronger, included fine sediment influx affecting macrophyte and diatoms in UK rivers, and temperature increase affecting sensitive invertebrate taxa in Greek rivers. All other combinations were more ambiguous, with the $\%$ AES median being almost zero, indicating stressor effects of roughly equal size.

The pattern of nutrient stress outweighing the effects of hydrological or morphological stress for river autotrophs is similar to lakes. Here, "the response variable matters" $38-$ while river autotrophs have shown to be responsive to hydrological or morphological stress elsewhere (e.g. 39,40), their effect size was overruled by the nutrient signal in our study. In one case, however, hydropeaking outweighed the nutrient signal on river autotrophs. The immediate mechanical effect of flush flows is very pervasive, but presumably limited to short river stretches downstream of a hydropower dam.

By contrast, river heterotrophs were equally affected by paired stressors when nutrient enrichment was paired with either hydrological, morphological or (to a lesser degree) thermal stress. This indicates that these paired stressors co-act on oxygen contents or habitat availability. In our study, we found small but consistent antagonistic interactions, in particular for channelized rivers, probably due to increased current velocities facilitating the oxygen availability. In the case of toxic stress our conjectures on mechanistic pathways remain speculative. The diversity of compound-specific modes of action across xenobiotics in each mixture renders toxic stress a multi-stressor issue in itself 41 . Notably, the toxic effects of ambient mixtures were clearly discernible in all respective paired-stressor case studies $(n=17)$, despite the likely different stressor modes of action42. Given the lack of adequate 
monitoring of xenobiotics, our findings support that toxic effects in the multiply-stressed

321 freshwaters of Europe are largely underestimated 43.

In summary, nutrient enrichment overrules the effects of most other stressors in lakes,

323 while the situation in rivers is more complex with plants being more strongly affected by

324 nutrients, while animals were equally affected by nutrient enrichment and other stressors.

\section{Conclusions}

327 Our study supports the conjecture that eutrophication is still the most relevant stressor 328 affecting many lakes, irrespective of the spatial scale considered. Other stressors are

329 subordinate but may reveal notable effects if interacting with nutrients. These deserve special

330 attention if antagonistic (e.g. lake brownification) and synergistic interactions (e.g. climate

331 warming) can be expected that control the overall nutrient effect on phytoplankton. Relevant

332 stressors and stressor combinations are more variable in rivers and more strongly affected by

333 spatial scales. While river autotrophs are mainly impacted by nutrients, heterotrophs seem to

334 be mainly influenced by oxygen availability that is impaired by a range of stressors (pollution,

335 warming, flow reduction and fine sediment entry) on top of nutrient enrichment. While

336 reduction of nutrient stress is most relevant for lakes, in particular under the conditions of

337 climate warming, rivers require mitigation measures addressing several stressors

338 simultaneously. Options include the establishment of woody riparian buffer strips that address

339 several stressors (eutrophication, hydromorphological degradation) simultaneously. 


\section{Case studies}

342 The 45 studies analysed here covered selected European lakes and rivers (including one 343 estuary) and addressed three spatial scales of investigation: manipulative multi-stressor 344 experiments in mesocosms and flumes, river basin studies and cross-basin studies (see 345 Figure 1, Supplementary Table 1). Several studies contributed to multiple analytical cases, 346 depending on the available combinations of stressors and responses. The number of cases 347 totalled 174.

The manipulative experiments were conducted within the framework of the European MARS project44, involving three lake mesocosm facilities in Denmark, Germany and United Kingdom, and four artificial flume facilities in Norway, Denmark, Austria and Portugal. The experiments applied controlled pairs of stressors to study the effects on selected biological response variables. Overall, 30 analytical cases and 1,498 sample replicates were considered in our analysis, with a median number of 79 sample replicates per study (range: 20 to 768 ).

The MARS project also contributed data on 14 river basin studies selected to cover the main European regions and their representative stressor combinations44. Based on harmonised analytical protocols 29 the multi-stressor effects were analysed using comprehensive datasets derived from regional monitoring programs. For this study we chose the most relevant pairedstressor response combinations from four lake catchments and ten river catchments that together provided 52 analytical cases with an overall number of 2,114 samples (median number of samples per basin: 97, range: 19 to 525).

The 22 cross-basin studies included in this analysis mostly originated from research activities, in which aquatic monitoring data was collated at regional, national or international level to investigate biological effects of various stressors (e.g.45,46). The spatial coverage of

364 these studies exceeded a single river basin, and commonly spanned large numbers of lakes and rivers. The number of analytical cases amounted to 92, comprising 14,486 samples (median number of samples per study: 374 , range: 40 to 3,706 ).

\section{Stressor variables}

Within this study we considered a "stressor" as any external factor modified by human intervention, which potentially moves a receptor (i.e. response variable) out of its normal operating range 47. The analysed stressor variables belonged to six stress categories (see also31): (1) nutrient stress (142 cases), including experimental addition or field sampling of

373 phosphorus or nitrogen compounds in the water; (2) hydrological stress (57 cases), including 
experimental manipulation or field measurement of high flow (e.g. high flow pulse duration),

375 low flow (e.g. residual flow), water level change, non-specific flow alteration (e.g. mean summer precipitation as proxy) and hydropeaking; (3) morphological stress (61 cases), including experimental treatment or field survey of river channel, bank and floodplain modification, and river connectivity disruption; (4) thermal stress (54 cases), including experimental heating or field measurement of water temperature (or air temperature as a proxy); (5) toxic stress of mixtures of xenobiotic compounds (18 cases), expressed as the multi-substance Potentially Affected Fraction41, Toxic Units48 or runoff potential49; and (6) other chemical stress (16 cases), including experimental application of humic substances and field samples of water quality determinants (e.g. dissolved oxygen, chloride, biological oxygen demand).

We always selected the stressor combinations most relevant for the respective broad lake or river type in the particular river basin or region, i.e. stressors that are most likely to affect biota due to their relative strength as compared to other regions and other stressors in the same region50 (see Supplementary Table 1). These included stressors prevalent in European freshwaters 20 and addressed in previous multi-stressor studies8. In the experimental studies, stressor intensities were applied emulating "real-life" conditions of the respective water body type. For instance, flumes mimicking nutrient-poor calcareous highland rivers were enriched by ten-fold phosphorus increase towards mesotrophic conditions - a realistic scenario in case of alpine pasture use in the floodplains. Mesocosms mimicking eutrophic shallow lowland lakes were enriched by five-fold phosphorus increase towards hypertrophic conditions - a realistic scenario in intensively used agricultural lowland landscapes. In the field studies, stressor intensities reflected the existing gradient in the particular river basin or region. Thus, the stressor "forcings" in all study cases represent conditions typical for the specific lake or river type, the river basin (featuring certain land uses) and the European region. In several of the investigated basins or cross-basins, more than two stressors were acting; in these we selected those that were assumed to affect the biota most strongly, either based on their intensity or based on previous studies on the relevance of the stressors in the region. combinations that only covered rivers (Table 1). For rivers, the combination of nutrient and morphological stress was the most frequent, amounting to more than one-third of cases. For lakes, the combination of nutrient and thermal stress was the most frequent, amounting to more than half of the cases. 


\section{Response variables}

A variety of organism groups was investigated, including phytoplankton (52 cases); benthic flora, i.e. macrophytes or phytobenthos (22); benthic invertebrates (63 cases); and fish (37 cases). Within the 174 cases, four categories of biological response variables were used: (1) biodiversity (76 cases), including indices reflecting the proportion of a taxonomic group within the assemblage (e.g. percentage of Chlorophyta in the benthic algal assemblage), taxon richness, Ecological Quality Ratios (as derived from ecological classification tools for the European Water Framework Directive) and taxon-sensitivity indices (e.g. saprobic indices, ASPT); (2) biomass/abundance (51 cases), including biomasses or total abundances of phytoplankton or fish, chlorophyll $a$ concentrations or cyanobacterial biomass; (3) functional traits (38 cases), including the absolute or relative abundance of functional groups such as habitat preferences, feeding types or life cycles and trait-based quality indices (e.g. SPEAR50); and (4) behaviour (9 cases), exclusively including drift rates of invertebrates and stranding rates of juvenile fish. While the response category "biodiversity" covered all organism groups, the category "biomass/abundance" was limited to phytoplankton (except for two cases each with benthic algae and fish), and both "functional traits" and "behaviour" were limited to animals (invertebrates and fish).

\section{Statistical analysis}

The relationship between the biological response and the paired stressors was investigated for each individual analytical case by GLM based on the general formula

$$
E(Y)=g-1\left(a \cdot x_{1}+b \cdot x_{2}+c \cdot x_{1} \cdot x_{2}\right)
$$

with $E(Y)$ is the expected value of the biological response variable $Y, g$ is the link function that specifies how the response relates to the linear predictors, $x_{1}$ is the standardized measurement of Stressor 1, $x_{2}$ is the standardized measurement of Stressor 2 and $x_{1} \cdot x_{2}$ is the interaction of the standardized measurements of Stressor 1 and Stressor 2. Parameters $a, b$ and $c$ scale the effects of Stressors 1,2 and their interaction, respectively.

\section{Data processing of stressor and response variables}

For large-scale data (multi-site biomonitoring data with no, or very short, temporal component), long-term average measures of stress were used. For multi-year data (single or multiple site), each year provided one stress measurement per site. When data was at higher temporal resolution, it was pre-processed to an annual level. Categorical stressor variables 
(e.g. experimental flow treatment) had only two levels representing stressed $v s$. unstressed 441 conditions.

442 All continuous variables (responses and stressor variables) were standardized by

443 transformation to approach normal distribution. A version of the Box-Cox transformation was 444 used51, including an offset to ensure strict positivity (all values $>0$ ). Transformed data was

445 inspected for normality by plotting frequency histograms. If the data exhibited skewness 446 because of extreme outliers, these outliers were excluded from the analysis. Following Box447 Cox transformation, each transformed variable was centred and scaled, so they had a mean of 448 zero and a variance of one.

Choice of regression model

451 The type of statistical model used to fit the paired-stressor response data depended on two 452 major considerations: (1) The type of analytical case, which determined whether a GLM was 453 sufficient or if a generalised linear mixed model (GLMM) with random effects was needed 454 (see Supplementary Table 2 for the criteria). GLMMs were used when the data structure 455 included grouping factors, such as experimental block, site or year (see “Data availability”). 456 In most cases the analyses included random effects in the standard way as random intercept 457 terms. However, if considered appropriate (e.g. due to large data volume) models with both 458 random intercepts and slopes were used. (2) The type of response data, which determined the 459 link function and error distribution of the model (Gaussian errors and an identity link for 460 continuous data, Poisson errors and a logarithmic link for count data). GLMs were fitted with 461 the base R libraries and GLMMs were fitted with the lme4 and lmerTest $\mathrm{R}$ packages.

\section{Testing and correcting for residual autocorrelation}

464 Where necessary, we tested whether model residuals showed strong evidence of spatial or 465 temporal autocorrelation, which can cause the statistical significance of model terms to be 466 exaggerated. This was only required when the analysis used GLMs without random effects, 467 since the random effects in the mixed effects models should account for grouping in space 468 and time. Autocorrelation in space or time was identified with Moran's tests on model 469 residuals and, where substantial autocorrelation was detected, the model was re-fitted 470 including a "trend surface" generated using a smoothing spline or polynomial functions52.

471 This is a simple and generally effective way of reducing the influence of autocorrelation on 472 the model's stressor effects of interest. 


\section{Model evaluation}

To evaluate our models, residuals were examined for correlation to the fitted values and deviation from the normal distribution (Shapiro-Wilk Test). We excluded 28 models where residuals were correlated with fitted values $(R>0.35)$ and non-normally distributed. Model fit was evaluated as the marginal $R 2$, i.e. the proportion of variance explained by the model fixed effects, ignoring the contribution of any random effects53. We excluded models with marginal $R_{2}<0.05$. Model fixed effects (main effects of both stressors and their interactions) were evaluated from the standardized partial regression coefficients and their significance ( $t$ Test), in the following referred to as standardised effect sizes (SES) (see "Data availability").

Several case studies allowed for analysing different response variables within the same organism group or across different organism groups, using datasets from the same river basin(s). To avoid redundancy in paired-stressor responses we checked that model results differed in marginal $\mathrm{R}_{2}$ and fixed effects.

\section{Importance of the interaction term}

The importance of the interaction term was estimated by the change in marginal $R_{2}$ upon dropping the interaction term, considered in cases with a significant interaction term, and expressed as a percentage change relative to the full model's marginal $R_{2}$ ( $\% R_{2}$ change).

\section{Interaction classification}

The type of interaction was characterised from the SES and only considered in case of a significant interaction term. We applied a simple classification scheme to the full model, referring to both stressors' main effects and their interaction. This was based on the direction of the interaction effect, relative to the directions of the main effects of both stressors. Synergistic interaction was assigned when the SES for both stressors and their interaction all had the same sign (i.e. all positive or all negative). Antagonistic interaction was assigned when SES for both stressors had the same sign, but their interaction had the opposite sign.

Opposing interaction was assigned when the signs of the SES for both stressors differed, and we distinguished between opposing contributing to either Stressor 1 (i.e. Stressor 1 and interaction with same sign) or Stressor 2 (i.e. Stressor 2 and interaction with same sign). Reversal interaction (sensu9,10) was assigned when the SES' sum for both stressors had a value smaller than and a sign different from the interaction's SES (see "Data availability"). 


\section{Synthesis analysis}

We identified the frequency of analytical cases with a significant interaction term ("interactive"), or where one ("dominance") or both stressors ("additive") were significant but not the interaction term. The importance (share) of these three types of stressor interrelations was compared between ecosystems (from studies of lakes or rivers) and between spatial scales (from experiments, basin and cross-basin studies). These comparisons were tested using the Chi-squared test. The distribution of marginal $R 2$ values from full models were compared between study scales, as well as the $\% R 2$ change for those cases with significant interaction terms. These comparisons were tested for significant differences using pairwise Mann-Whitney U-tests with Bonferroni correction for multiple comparisons.

To evaluate the relevance of nutrient enrichment in the paired-stressor context, we selected a subset of cases that included both nutrient stress paired with another stressor. The strength of their effect sizes was compared, distinguishing between effects on autotrophs and heterotrophs across lakes and rivers. In this analysis we simply considered the magnitude of the absolute effect sizes of the two stressors (and their interaction) rather than whether they had positive, negative or opposing effects on the response variable.

We calculated the relative absolute effect sizes per analytical case (\%AES) by setting the sum of the absolute SES of Stressor 1, Stressor 2 and their interaction to $100 \%$ (irrespective of their statistical significance in the regression analysis), and expressing the individual SES as a percentage. The difference between \%AES of the nutrient stressor and \%AES of the other stressor revealed which stressor had the stronger effect on the biological response, with positive values indicating stronger effects of nutrient enrichment, and negative values indicating stronger effects of the other stressors. In the case of an opposing interaction, the $\%$ AES of the interaction term was added to the stressor's \%AES with which the interaction SES shared the sign (e.g. the \%AES of a positive interaction SES was added to the \%AES of the nutrient stressor if its SES was also positive). In case of a synergistic or antagonistic interaction, we considered the interaction effect to be equally relevant for both stressors with no implications for the difference in the individual stressor effects. available at GitHub: https://github.com/sebastian-birk/MultiStressorImpacts.

Code availability: The R-script is available at GitHub: https://github.com/sebastian-birk/MultiStressorImpacts.

Acknowledgements: This work was supported by the MARS project (Managing Aquatic ecosystems and water Resources under multiple Stress) funded under the 7th EU Framework Programme, Theme 6 (Environment including Climate Change), Contract No: 603378 (http://www.mars-project.eu). 25\% co-funding was provided by partner organisations through their institutional budgets. We are grateful for the constructive comments provided by Abel Barral Cuesta and the anonymous reviewers, and we thank Jörg Strackbein, Jelka Lorenz and Leoni Mack for their support. 


\section{Author contributions}

Study conceptualisation: D.C., L.C., B.M.S., S.B., L.B., S.J.T., D.H.; data curation: D.C., S.B.; funding acquisition and project administration: D.H., L.C., S.B.; data provision and/or formal analysis: A.B., A.G., A.S., B.M.S., C.A., C.G.-C., C.P., D.d.Z., D.G., E.B.-K., F.C., G.P., J.J.R., J.R., J.T., J.U.L., K.R., K.S., L.P., L.S., M.C.U., M.J., N.K., N.W., P.B., P.S., P.C.v.d.O., R.B.S., R.-M.C., R.S., S.A., S.B., S.C.S., S.J.M., S.L., S.P., S.J.T., T.B., U.I., U.M.; experimental investigations: A.B.-P., A.L.S., D.G., E.B.-K., E.J., H.F., J.M.S., J.R., L.C., L.S., M.G., P.B., S.A., S.C.S., S.S., W.G.; manuscript writing: S.B., D.H., B.M.S., M.G., D.C.; H.E.A., M.B., A.D.B., A.C.C., C.K.F., M.T.F., M.O.G., L.G., J.H., M.K., P.N., T.N., S.J.O., Y.P., B.S., M.V. and aforementioned authors reviewed the manuscript and provided necessary amendments.

Competing interests: The authors declare no competing interests.

\section{References}

1. Ormerod, S.J., Dobson, M., Hildrew, A.G., Townsend, C.R., 2010. Multiple stressors in freshwater ecosystems. Freshw. Biol. 55, 1-4. https://doi.org/10.1111/j.13652427.2009.02395.x

2. Côté, I.M., Darling, E.S., Brown, C.J., 2016. Interactions among ecosystem stressors and their importance in conservation. Proc. R. Soc. B Biol. Sci. 283, 20152592.

https://doi.org/10.1098/rspb.2015.2592

3. van Dijk, G.M., van Liere, L., Admiraal, W., Bannink, B.A., Cappon, J.J., 1994. Present state of the water quality of European rivers and implications for management. Sci. Total Environ. 145, 187-195. https://doi.org/10.1016/0048-9697(94)90309-3

4. Richardson, J., Miller, C., Maberly, S.C., Taylor, P., Globevnik, L., Hunter, P., Jeppesen, E., Mischke, U., Moe, S.J., Pasztaleniec, A., Søndergaard, M., Carvalho, L., 2018. Effects of multiple stressors on cyanobacteria abundance varies with lake type. Glob. Chang. Biol. 24, 5044-5055. https://doi.org/10.1111/gcb.14396

5. Schäfer, R.B., Kühn, B., Malaj, E., König, A., Gergs, R., 2016. Contribution of organic toxicants to multiple stress in river ecosystems. Freshw. Biol. 61, 2116-2128. https://doi.org/10.1111/fwb.12811

6. Schinegger, R., Palt, M., Segurado, P., Schmutz, S., 2016. Untangling the effects of multiple human stressors and their impacts on fish assemblages in European running waters. Sci. Total Environ. 573, 1079-1088. https://doi.org/10.1016/j.scitotenv.2016.08.143

7. Folt, C.L., Chen, C.Y., Moore, M. V, Burnaford, J., Henry, R., Hall, J., Baumgartner, K., 1999. Synergism and antagonism among multiple stressors. Limnol. Oceanogr. 44, 864-877. http://dx.doi.org/10.4319/lo.1999.44.3_part_2.0864

8. Nõges, P., Argillier, C., Borja, Á., Garmendia, J.M., Hanganu, J., Kodeš, V., Pletterbauer, F., Sagouis, A., Birk, S., 2016. Quantified biotic and abiotic responses to multiple stress in freshwater, marine and ground waters. Sci. Total Environ. 540, 43-52.

https://doi.org/10.1016/j.scitotenv.2015.06.045

\section{Piggott, J.J., Townsend, C.R., Matthaei, C.D., 2015. Reconceptualizing synergism and} antagonism among multiple stressors. Ecol. Evol. 5, 1538-1547. https://doi.org/10.1002/ece3.1465

10. Jackson, M.C., Loewen, C.J.G., Vinebrooke, R.D., Chimimba, C.T., 2016. Net effects of multiple stressors in freshwater ecosystems: a meta-analysis. Glob. Chang. Biol. 22, 180-189. https://doi.org/10.1111/gcb.13028

11. de Laender, F., 2018. Community- and ecosystem-level effects of multiple environmental change drivers: beyond null model testing. Glob. Chang. Biol. 1-10.

https://doi.org/10.1111/gcb.14382 

Mannio, J., Monteith, D.T., Mosello, R., Rogora, M., Rzychon, D., Vesely, J., Wieting, J., Wilander, A., Worsztynowicz, A., 2005. Regional scale evidence for improvements in surface water chemistry 1990-2001. Environ. Pollut. 137, 165-176.

594 https://doi.org/10.1016/j.envpol.2004.12.023

13. Reid, A.J., Carlson, A.K., Creed, I.F., Eliason, E.J., Gell, P.A., Johnson, P.T.J., Kidd, K.A., MacCormack, T.J., Olden, J.D., Ormerod, S.J., Smol, J.P., Taylor, W.W., Tockner, K., Vermaire, J.C., Dudgeon, D., Cooke, S.J., 2019. Emerging threats and persistent conservation challenges for freshwater biodiversity. Biol. Rev. 94, 849-873.

https://doi.org/10.1111/brv.12480

600

601

602

603

604

605

606

607

608

609

610

611

612

613

614

615

616

617

618

619

620

621

622

623

624

625

626

627

628

629

630

631

632

633

14. Palmer, M. A., Menninger, H.L., Bernhardt, E., 2010. River restoration, habitat heterogeneity and biodiversity: a failure of theory or practice? Freshw. Biol. 55, 205-222. https://doi.org/10.1111/j.1365-2427.2009.02372.x

15. Vinebrooke, R., Cottingham, K., Norberg, M., 2004. Impacts of multiple stressors on biodiversity and ecosystem functioning: the role of species co-tolerance. Oikos 3, 451-457. https://doi.org/10.1111/j.0030-1299.2004.13255.x

16. Schäfer, R.B., Piggott, J.J., 2018. Advancing understanding and prediction in multiple stressor research through a mechanistic basis for null models. Glob. Chang. Biol. 24, 18171826 https://doi.org/10.1111/gcb.14073

17. Thorp, J.H., Thoms, M.C., Delong, M.D., 2006. The riverine ecosystem synthesis: biocomplexity in river networks across space and time. River Res. Appl. 22, 123-147. https://doi.org/10.1002/rra.901

18. Brucet, S., Pédron, S., Mehner, T., Lauridsen, T.L., Argillier, C., Winfield, I.J., Volta, P., Emmrich, M., Hesthagen, T., Holmgren, K., Benejam, L., Kelly, F., Krause, T., Palm, A., Rask, M., Jeppesen, E., 2013. Fish diversity in European lakes: geographical factors dominate over anthropogenic pressures. Freshw. Biol. 58, 1779-1793.

19. Feld, C.K., Birk, S., Eme, D., Gerisch, M., Hering, D., Kernan, M., Maileht, K., Mischke, U., Ott, I., Pletterbauer, F., Poikane, S., Salgado, J., Sayer, C.D., Van Wichelen, J., Malard, F., 2016. Disentangling the effects of land use and geo-climatic factors on diversity in European freshwater ecosystems. Ecol. Indic. 60, 71-83. https://doi.org/10.1016/j.ecolind.2015.06.024

20. EEA, 2018. European waters: Assessment of status and pressures 2018. EEA Report 7/2018, European Environment Agency, Copenhagen, 90 pp. https://www.eea.europa.eu/publications/state-of-water/

21. Jeppesen, E, Sondergaard, M, Jensen, JP, Havens, KE, Anneville, O, Carvalho, L, Coveney, MF, Deneke, R, Dokulil, MT, Foy, B, Gerdeaux, D, Hampton, SE, Hilt, S, Kangur, K, Kohler, J, Lammens, EHHR, Lauridsen, TL, Manca, M, Miracle, MR, Moss, B, Nõges, P, Persson, G, Phillips, G, Portielje, R, Schelske, CL, Straile, D, Tatrai, I, Willen, E, Winder, M. (2005) Lake responses to reduced nutrient loading - an analysis of contemporary long-term data from 35 case studies. Freshwater Biology 50, 1747-1771.

22. Hering, D., Johnson, R.K., Kramm, S., Schmutz, S., Szoszkiewicz, K. \& Verdonschot, P.F.M. (2006) Assessment of European rivers with diatoms, macrophytes, invertebrates and fish: A comparative metric-based analysis of organism response to stress. Freshwater Biology $51,1757-1785$. 

Rethinking our approach to multiple stressor studies in marine environments. Mar. Ecol. Prog. Ser. 543, 273-281. https://doi.org/10.3354/meps 11595

24. Davies, B.R., Biggs, J., Williams, P.J., Lee, J.T., Thompson, S., 2008. A comparison of the catchment sizes of rivers, streams, ponds, ditches and lakes: implications for protecting aquatic biodiversity in an agricultural landscape. Hydrobiologia 597, 7-17.

640 https://doi.org/10.1007/s10750-007-9227-6

641

642

643

644

645

646

647

648

649

650

651

652

653

654

655

656

657

658

659

660

661

662

663

664

665

666

667

668

669

670

671

672

673

674

675

676

677

678

679

25. Fuller, I.C., Death, R.G., 2018. The science of connected ecosystems: What is the role of catchment-scale connectivity for healthy river ecology? L. Degrad Dev. 29, 1413-1426. https://doi.org/10.1002/ldr.2903

26. Benda, L., Poff, N.L., Miller, D., Dunne, T., Reeves, G., Pess, G., Pollock, M., 2004. The network dynamics hypothesis: How channel networks structure riverine habitats. Bioscience 54, 413-427. https://doi.org/10.1641/0006-3568(2004)054[0413:TNDHHC]2.0.CO;2

27. Liess, M., Brown, C., Dohmen, P., Duquesne, S., Hart, A., Heimbach, F., Kreuger, J., Lagadic, L., Maund, S., Reinert, W., Streloke, M., Tarazona, J.V., 2005. Effects of pesticides in the field. Society of Environmental Toxicology and Chemistry (SETAC), Brussels, 136 p. ISBN: 1-880611-81-3

29. Price, K.J., Carrick, H.J., 2016. Effects of experimental nutrient loading on phosphorus uptake by biofilms: Evidence for nutrient saturation in mid-Atlantic streams. Freshw. Sci. 35, 503-517. https://doi.org/10.1086/686269

30. McCall, S.J., Hale, M.S., Smith, J.T., Read, D.S., Bowes, M.J., 2017. Impacts of phosphorus concentration and light intensity on river periphyton biomass and community structure. Hydrobiologia 792, 315-330. https://doi.org/10.1007/s10750-016-3067-1

31. Birk, S., 2019. Detecting and quantifying the impact of multiple stress on river ecosystems. In: Sabater, S., Ludwig, R., Elosegi, A. (Eds.), Multiple Stress in River Ecosystems. Status, Impacts and Prospects for the Future. Academic Press, Oxford, pp. 235253. https://doi.org/10.1016/B978-0-12-811713-2.00014-5

32. Birk, S., Bonne, W., Borja, A., Brucet, S., Courrat, A., Poikane, S., Solimini, A., Van De Bund, W., Zampoukas, N., Hering, D., 2012. Three hundred ways to assess Europe's surface waters: An almost complete overview of biological methods to implement the Water Framework Directive. Ecol. Indic. 18, 31-41. https://doi.org/10.1016/j.ecolind.2011.10.009

33. Moss, B., Kosten, S., Meerhoff, M., Battarbee, R.W., Jeppesen, E., Mazzeo, N., Havens, K., Lacerot, G., Liu, Z., Meester, L. De, Paerl, H., Scheffer, M., 2011. Allied attack: climate change and eutrophication. Inl. Waters 1, 101-105. https://doi.org/10.5268/IW-1.2.359

34. Richardson, J., Feuchtmayr, H., Miller, C., Hunter, P.D., Maberly, S.C., Carvalho L., 2019. The response of cyanobacteria and phytoplankton abundance to warming, extreme rainfall events and nutrient enrichment. Glob. Chang. Biol. 25, 3365-3380. www.doi.org/10.1111/gcb.14701

35. Jeppesen, E., Meerhoff, M., Holmgren, K., González-Bergonzoni, I., Teixeira-de Mello, F., Declerck, S.A.J., De Meester, L., Søndergaard, M., Lauridsen, T.L., Bjerring, R., CondePorcuna, J.M., Mazzeo, N., Iglesias, C., Reizenstein, M., Malmquist, H.J., Liu, Z., Balayla, D., Lazzaro, X., 2010. Impacts of climate warming on lake fish community structure and potential effects on ecosystem function. Hydrobiologia 646, 73-90. https://doi.org/10.1007/s10750-010-0171-5

36. Monteith, D.T., Stoddard, J.L., Evans, C.D., De Wit, H.A., Forsius, M., Høgåsen, T., Wilander, A., Skjelkvåle, B.L., Jeffries, D.S., Vuorenmaa, J., Keller, B., Kopécek, J., Vesely, 
680

681

682

683

684

685

686

687

688

689

690

691

692

693

694

695

696

697

698

699

700

701

702

703

704

705

706

707

708

709

710

711

712

713

714

715

716

J., 2007. Dissolved organic carbon trends resulting from changes in atmospheric deposition chemistry. Nature 450, 537-540. https://doi.org/10.1038/nature06316

37. Graneli, W., 2012. Brownification of Lakes, in: Bengtsson, L., Herschy, R.W., Fairbridge, R.W. (Eds.), Encyclopedia of Lakes and Reservoirs. Springer Netherlands, Dordrecht, pp. 117-119. https://doi.org/10.1007/978-1-4020-4410-6_256

38. Segner, H., Schmitt-Jansen, M., Sabater, S., 2014. Assessing the Impact of Multiple Stressors on Aquatic Biota: The Receptor's Side Matters. Environ. Sci. Technol. 48, 76907696. https://doi.org/10.1021/es405082t

39. Baattrup-Pedersen, A., Riis, T., 1999. Macrophyte diversity and composition in relation to substratum characteristics in regulated and unregulated Danish streams. Freshw. Biol. 42, 375-385. https://doi.org/10.1046/j.1365-2427.1999.444487.x

40. Schneider, S.C., Sample, J.E., Moe, J.S., Petrin, Z., Meissner, T., Hering, D., 2018. Unravelling the effect of flow regime on macroinvertebrates and benthic algae in regulated versus unregulated streams. Ecohydrology 11, e1996. https://doi.org/10.1002/eco.1996 41. de Zwart, D., Posthuma, L., 2005. Complex mixture toxicity for single and multiple species: Proposed methodologies. Environ. Toxicol. Chem. 24, 2665-2676. https://doi.org/10.1897/04-639R.1

42. Busch, W., Schmidt, S., Kühne, R., Schulze, T., Krauss, M., Altenburger, R., 2016. Micropollutants in European rivers: A mode of action survey to support the development of effect-based tools for water monitoring. Environmental Toxicology and Chemistry 35, 18871899. https://doi.org/10.1002/etc. 3460

43. Malaj, E., von der Ohe, P.C., Grote, M., Kühne, R., Mondy, C.P., Usseglio-Polatera, P., Brack, W., Schäfer, R.B., 2014. Organic chemicals jeopardize the health of freshwater ecosystems on the continental scale. Proc. Natl. Acad. Sci. 111, 9549-9554. https://doi.org/10.1073/pnas.1321082111

44. Hering, D., Carvalho, L., Argillier, C., Beklioglu, M., Borja, A., Cardoso, A.C., Duel, H., Ferreira, T., Globevnik, L., Hanganu, J., Hellsten, S., Jeppesen, E., Kodeš, V., Solheim, A.L., Nõges, T., Ormerod, S., Panagopoulos, Y., Schmutz, S., Venohr, M., Birk, S., 2015. Managing aquatic ecosystems and water resources under multiple stress - An introduction to the MARS project. Sci. Total Environ. 503, 10-21. https://doi.org/10.1016/j.scitotenv.2014.06.106

45. Moe, S.J., Dudley, B., Ptacnik, R., 2008. REBECCA databases: experiences from compilation and analyses of monitoring data from 5,000 lakes in 20 European countries. Aquat. Ecol. 42, 183-201. https://doi.org/10.1007/s10452-008-9190-y

46. Moe, S.J., Schmidt-Kloiber, A., Dudley, B.J., Hering, D., 2013. The WISER way of organising ecological data from European rivers, lakes, transitional and coastal waters. Hydrobiologia 704, 11-28. https://doi.org/10.1007/s10750-012-1337-0

47. Sabater, S., Ludwig, R., Elosegi, A., 2019. Defining multiple stressor implications. In: Sabater, S., Ludwig, R., Elosegi, A. (Eds.), Multiple Stress in River Ecosystems. Status, Impacts and Prospects for the Future. Academic Press, Oxford, pp. 1-22.

https://doi.org/10.1016/B978-0-12-811713-2.00001-7

48. Liess, M., von der Ohe, P.C., 2005. Analyzing Effects of Pesticides on Invertebrate Communities in Streams. Environ. Toxicol. 24, 954-965. https://doi.org/10.1897/03-652.1

49. von der Ohe, P.C., Goedkoop, W., 2013. Distinguishing the effects of habitat degradation and pesticide stress on benthic invertebrates using stressor-specific metrics. Sci. Total Environ. 444, 480-490. https://doi.org/10.1016/j.scitotenv.2012.12.001 
50. Lyche Solheim, A., Globevnik, L., Austnes, K., Kristensen, P., Moe, S.J., Persson, J., Phillips, G., Poikane, S., van de Bund, W., Birk, S., 2019. A new broad typology for rivers and lakes in Europe: Development and application for large-scale environmental assessments. Sci. Total Environ. 697. https://doi.org/10.1016/j.scitotenv.2019.134043

730 51. Box, G.E.P., Cox, D.R., 1964. An analysis of transformations. J. R. Stat. Soc. Ser. B 26, 731 211-252. https://www.jstor.org/stable/2984418

732 52. Dormann, C.F., McPherson, J., Araújo, M.B., Bivand, R., Bolliger, J., Carl, G., Davies, 733 R.G., Hirzel, A., Jetz, W., Kissling, D., Kühn, I., Ohlemüller, R., Peres-Neto, P.R., Reineking, 734 B., Schröder, B., M. Schurr, F., Wilson, R., 2007. Methods to account for spatial 735 autocorrelation in the analysis of species distributional data: A review. Ecography (Cop.). 30, 736 609-628. https://doi.org/10.1111/j.2007.0906-7590.05171.x

737 53. Nakagawa, S., Schielzeth, H., 2013. A general and simple method for obtaining R2 from 738 generalized linear mixed-effects models. Methods in Ecology and Evolution 4, 133-142.

739 https://doi.org/10.1111/j.2041-210x.2012.00261.x 


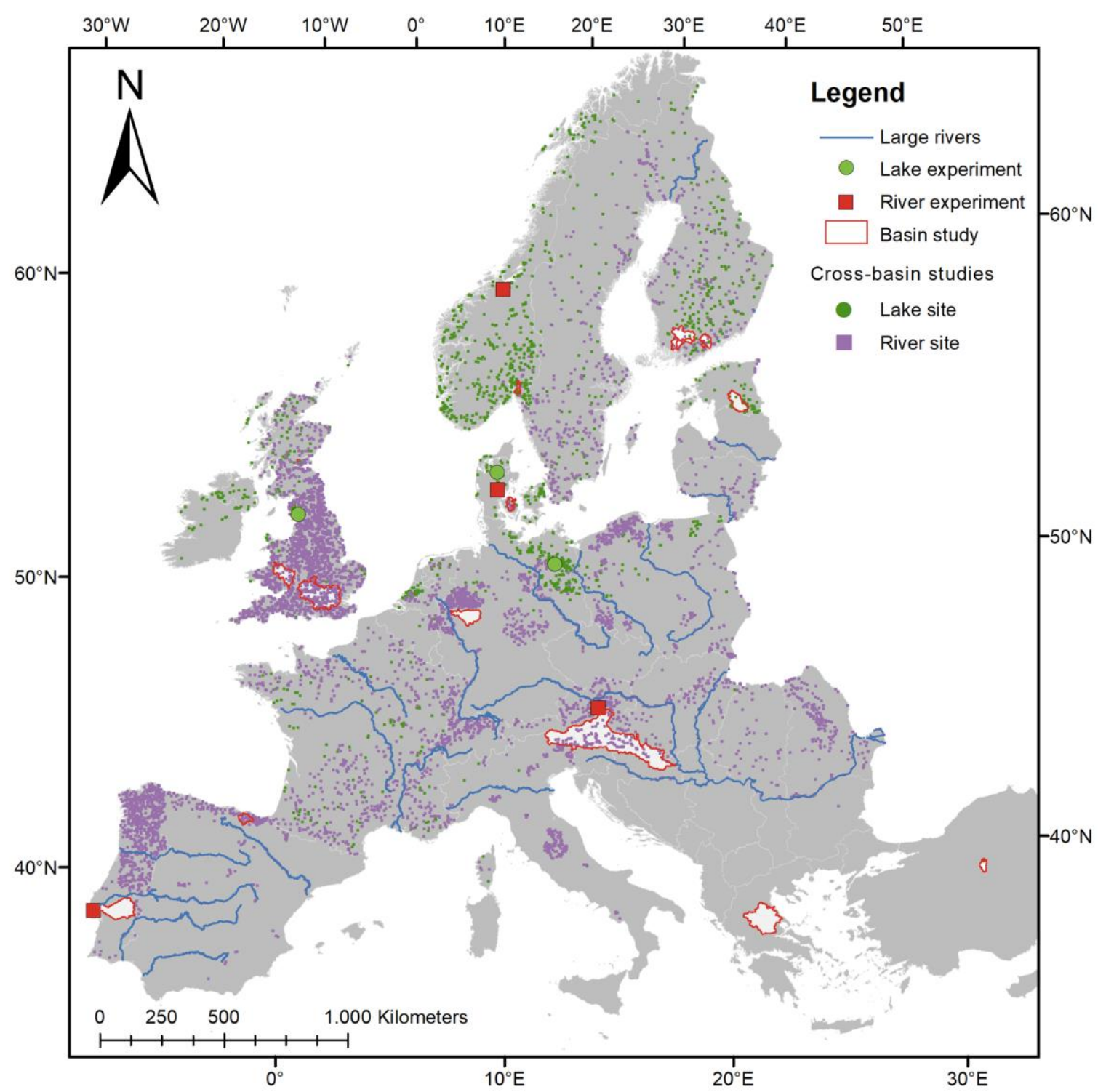

745 Figure 1: Location of the seven experimental facilities, 14 basin studies and sampling sites

746 (small dots) for the 22 cross-basin studies of lakes and rivers across Europe (see

747 Supplementary Table 1 for details). 


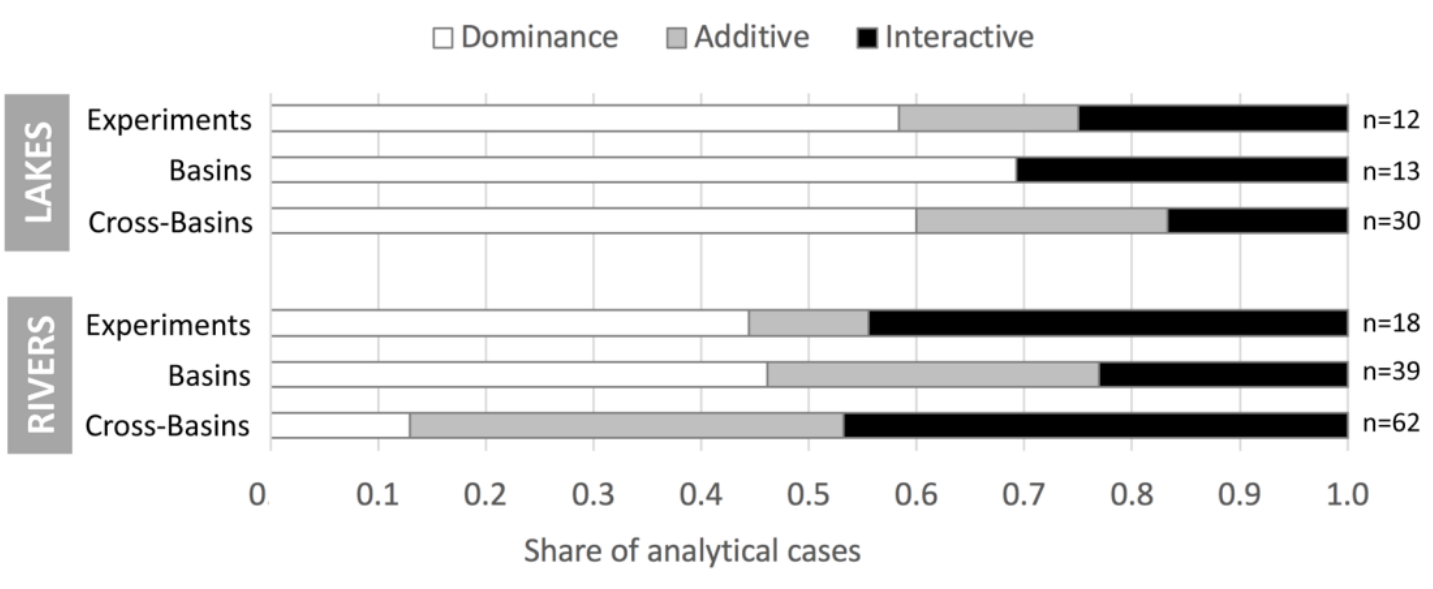

750 Figure 2: Share of analytical cases across experiments, basin studies and cross-basin studies

751 from lakes $(\mathrm{n}=55)$ and rivers $(\mathrm{n}=119)$, for which only a single stressor (dominance), both

752 stressors (additive) or their interaction significantly contributed to the variability of the

753 biological response.

754 


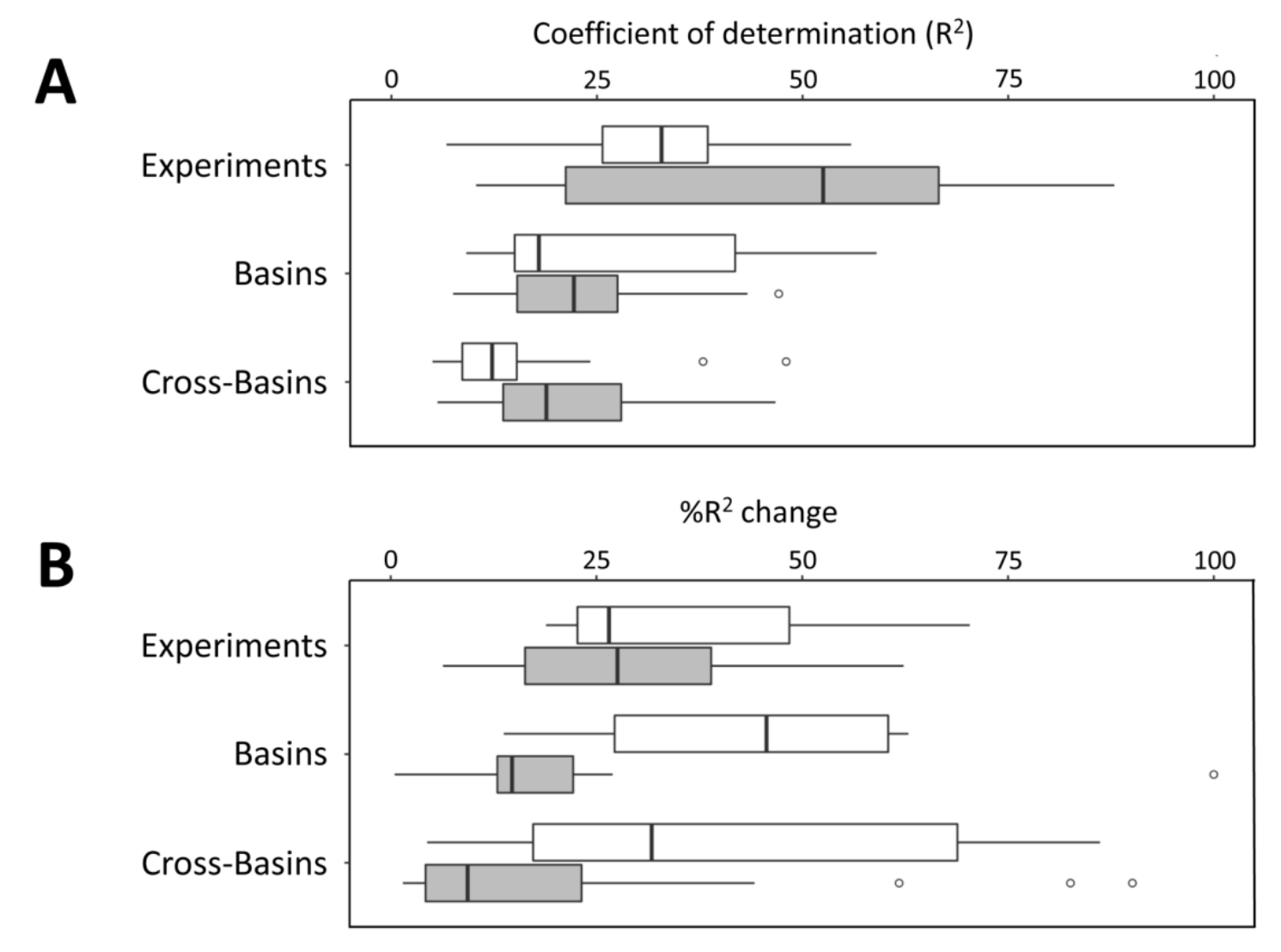

756 Figure 3: (A) Percent of biological variance explained by the paired stressors including their

757 interaction for the mesocosm experiments $(n=30)$, basin study cases $(n=52)$ and cross-

758 basin study cases $(n=92)$, separately for lakes (white boxes) and rivers (grey boxes). Lakes

759 and rivers differ significantly only for the cross-basin studies (pairwise Bonferroni-corrected

760 Mann-Whitney U-test, $p=0.001)$.

761 (B) Percent change in explained biological variance when interaction term is removed from

762 the model (in case of a significant interaction term) for the mesocosm experiments $(n=11)$,

763 basin study cases $(n=13)$ and cross-basin study cases $(n=34)$, separately for lakes (white

764 boxes) and rivers (grey boxes). None of the differences within spatial scales are significant.

765 Definition of box-plot elements: centre line = median; box limits = upper and lower quartiles;

766 whiskers $=1.5 \mathrm{x}$ interquartile range; points $=$ outliers. 


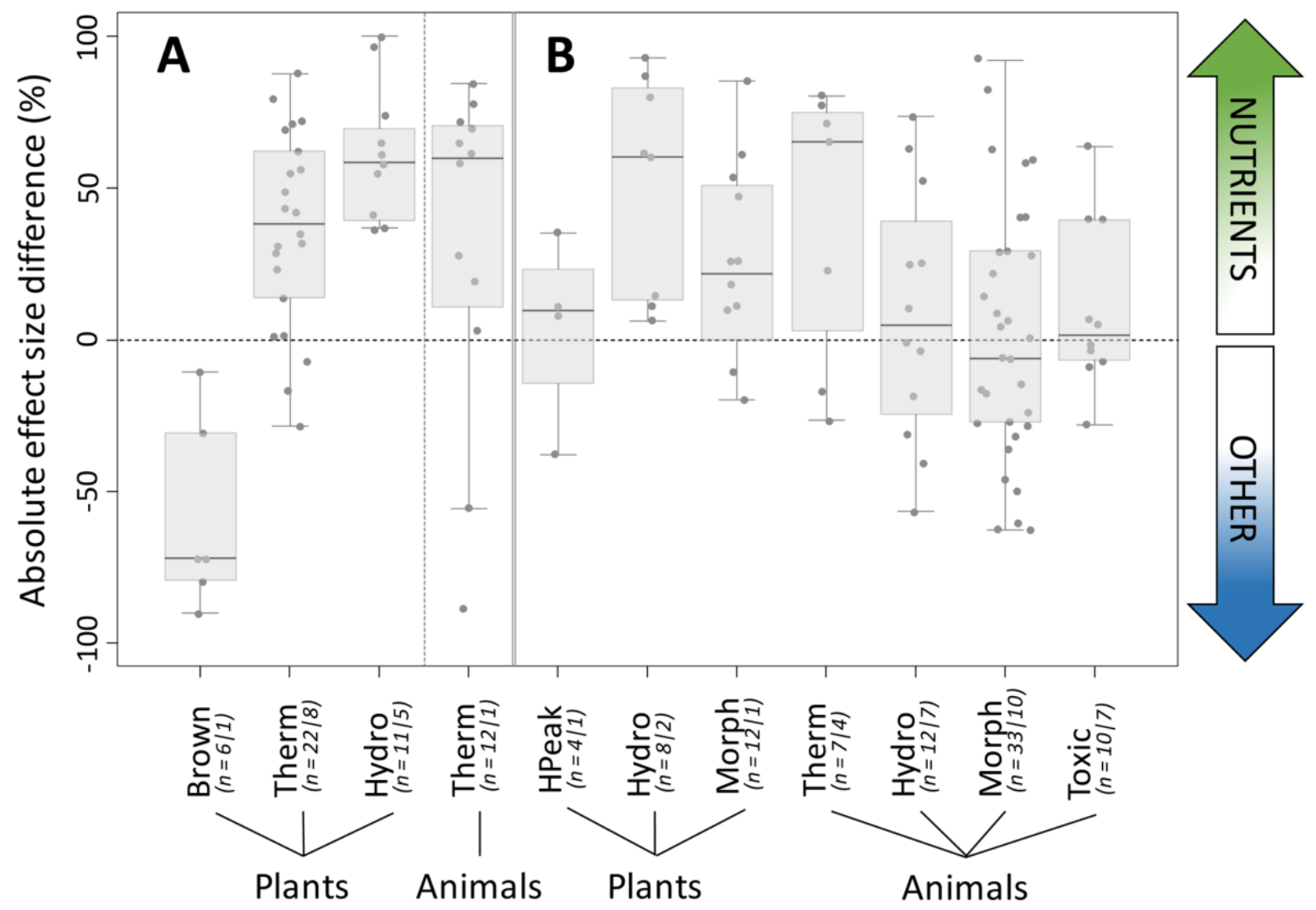

769 Figure 4: Range of absolute effect size differences (\%AES) for nutrient stress and selected 770 other stressors across case-studies from (A) lakes and (B) rivers. Positive \%AES indicate 771 stronger effects by nutrient stress, negative \%AES indicate stronger effects by the other 772 stressor on the biological response variable (subdivided into plants and animals) in the 773 regression model.

774 Brown $=$ Brownification, Therm $=$ Thermal stress, HPeak $=$ Hydropeaking, Hydro $=$ Hydrological 775 stress, Morph $=$ Morphological stress, Toxic $=$ Toxic stress $; n=$ Number of analytical cases $\mid$ case 776 studies.

777 Definition of plot elements: box centre line $=$ median; box limits $=$ upper and lower quartiles; whiskers $=1.5 \mathrm{x}$ 778 interquartile range; points $=$ individual analytical cases. 